\title{
Development of High Temperature Superconducting Current Feeders for a Large-scale Superconducting Experimental Fusion System
}

\author{
T. Mito, K. Takahata, R. Heller, A. Iwamoto, R. Maekawa, H. Tamura, Y. Yamada, K. Tachikawa, \\ K. Maehata, K. Ishibashi, G. Friesinger, M. Tasca, A. Nishimura, S. Yamada, S. Imagawa, N. Yanagi, \\ H. Chikaraishi, S. Hamaguchi, M. Takeo, T. Shintomi, T. Satow, and O. Motojima
}

\begin{abstract}
The National Institute for Fusion Science (NIFS), in collaboration with universities and laboratories in Japan, the Forschungszentrum Karlsruhe (FZK) and the Max-Planck Institut für Plasma Physik (IPP) in Germany, is planning to develop High Temperature Superconducting (HTS) current feeders for large-scale superconducting coils. Two programs are being progressed: one is a current feedthrough for superfluid helium (He II) cooled superconducting coils; the other is current leads for experimental fusion system. The paper describes the present status of the two programs, including joint experiments of a $20 \mathrm{kA}$ Bi-2223 current lead developed by FZK and development of a prototype YBCO bulk current feedthrough for He II cooled superconducting coils. In addition, the test results of $\mathrm{Bi}-2212$ tubes fabricated by diffusion process, applicable to HTS current leads, are described.
\end{abstract}

Index Terms- High-temperature superconductor, current feeder, current lead, fusion system.

\section{INTRODUCTION}

$\mathrm{L}$ arge-scale superconducting systems, such as experimental fusion devices, consist of multiple superconducting coils. The current supplied to coils becomes large capacity according to the increase in a magnetic stored energy. Since multiple large current feeders are needed, they may dominate the heat load to a cryogenic system. Current feeder, which connect power supplies to superconducting coils, are composed of current leads, bus lines, current feedthroughs and coil leads. If a high-temperature superconductor (HTS) can be used for a current feeder, it can satisfy the requirement of stable large current transport capability and low heat load, simultaneously.

Manuscript received September 18, 2000. Part of this work have been supported by a Grant-in-Aid for Scientific Research (\#11210209)

T. Mito, K. Takahata, A. Iwamoto, R. Maekawa, H. Tamura, A. Nishimura, S. Yamada, S. Imagawa, N. Yanagi, H. Chikaraishi, S. Hamaguchi, T. Satow, and O. Motojima are with the National Institute for Fusion Science (NIFS), Toki, Gifu 509-5292, Japan (telephone: +81-572-2123, e-mail: mito@nifs.ac.jp)

R. Heller, G. Friesinger, and $M$. Tasca are with the Forschungszentrum Karlsruhe, Institut für Technische Physik (ITP), D-76021 Karlsruhe, Germany (telephone: +49-7247-822701, e-mail: reinhard.heller @itp.fzk.de).

Y. Yamada, and K. Tachikawa are with Tokai University, Hiratsuka, Kanagawa 259-12, Japan

K. Maehata, K. Ishibashi, and M. Takeo are with Kyushu University, Fukuoka 812-8581, Japan.

T. Shintomi is with the High Energy Accelerator Research Organization (KEK), Tsukuba, Ibaraki 305-0801, Japan

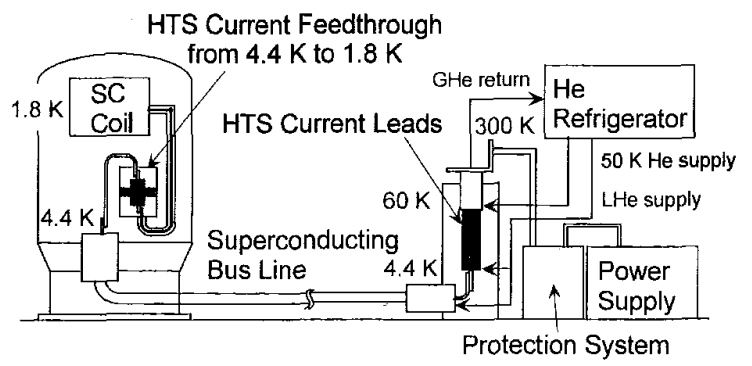

Fig. 1. Setup of a HTS current feeder for LHD in phase II experiment.

\section{DEVELOPMENT ProgRam For HTS CURRENT FEEDER}

In the phase II experiment of the Large Helical Device (LHD) of the National Institute for Fusion Science (NIFS), it is planned to increase a plasma central field from $3 \mathrm{~T}$ to $4 \mathrm{~T}$ by cooling the helical coils from $4.4 \mathrm{~K}$ to $1.8 \mathrm{~K}$ using pressurized superfluid helium (He II). Fig. 1 shows a typical setup of the current feeder, which will be necessary for LHD in phase II experiment. Two research programs are being progressed at NIFS.

The first program is a development of a HTS current feedthrough for the helical coil from $4.4 \mathrm{~K}$ to $1.8 \mathrm{~K}$. The high-purity aluminum stabilizer of the helical coil conductor has high thermal conductivity $(\sim 20 \mathrm{~kW} / \mathrm{m} \cdot \mathrm{K})$. The heat leak from $\mathrm{He} \mathrm{I}$ to the $\mathrm{He}$ II environment through the aluminum-stabilized superconductor can be reduced significantly by using HTS $(\sim 0.2 \mathrm{~W} / \mathrm{m} \cdot \mathrm{K})$ current feedthrough. The development is being carried out as a domestic collaboration with universities and laboratories centering on Kyushu University.

The second program is a development of HTS current leads, which cover the low temperature part of current leads from $4.4 \mathrm{~K}$ to $60 \mathrm{~K}$. The nominal current of the helical coils increases to $17.3 \mathrm{kA}$ and the maximum current of poloidal coils becomes $31.3 \mathrm{kA}$ in phase II experiment. Six pairs of current leads are necessary for the helical coils, while three pairs of them are required for the poloidal field coils. If helium gas cooled conventional copper current leads are used, it becomes a large heat load, which consumes $650 \mathrm{~L} / \mathrm{h}$ liquid helium. By using HTS current leads, this heat load could be reduced to about $1 / 4$ of them. The development is progressed in the frame of the LHD International Mutual Experiment (LIME) with the Forschungszentrum Karlsruhe (FZK) and the Max-Planck Institut für Plasma Physik (IPP) in Germany, and universities and laboratories in Japan centering on Tokai University. 


\section{JOINT EXPERIMENTS OF $20 \mathrm{KA}$ BI-2223 CURRENT LEAD}

\section{A. Experimental Setup}

A $20 \mathrm{kA}$ HTS current lead, made of $\mathrm{Ag} / \mathrm{Au}$ stabilized $\mathrm{Bi}-2223$ tapes, has been developed by FZK. It is designed to prove the modularity and scale-ability of $60 \mathrm{kA}$ current leads for the ITER toroidal field coil system. The HTS current lead is a hybrid type, which consists of a copper upper stage and an HTS lower stage. The upper stage is cooled by the forced flow helium gas, which enters from the metal-to-HTS connection. The HTS itself is not actively cooled but cooled by conduction from the cold end.

The performance tests of 20kA HTS current leads were conducted in NIFS with FZK, as collaboration in LIME. Accompanied paper [1] describes the design and the tests results of the current lead, while this paper presents the experimental setup and the procedure with some results.

Fig. 3 shows a test cryostat for the HTS current lead, which was designed and used to test model poloidal field coils of LHD. The $20 \mathrm{kA}$ HTS current lead was installed in the test cryostat with a $30 \mathrm{kA}$ conventional copper current lead. A SC bus bar, a prototype Cable-in-Conduit conductor for the Wendelstein 7-X, was used to connect the current leads at the ends. Thermal radiation shields cooled by liquid nitrogen were installed in the cryostat to minimize radiation heat leak.

Fig. 4 shows a schematic of the cryogenic system for the performance test. The intercept temperature of the HTS lead, T4, was controlled by the heater to establish various conditions. Control valves V4 and V5 adjusted the mass flow rate, F4, depending on the excitation current. Forced-flow supercritical helium was supplied to maintain the temperatures of both the SC bus bar and HTS lead terminal by control valves; V2 and V3. The heat leak to the HTS terminal could be estimated with the supercritical helium enthalpy change, using T1, P1 and T2, P2.

\section{B. Experimental Procedure and Results}

The experiments were conducted form May 30 to June 9, 2000 as summarized in Table I. Before starting the cool-down, the helium gas in the cryogenic system was purified for a week. The helium refrigerator had been operated throughout that period except for the weekend (June 3-4).

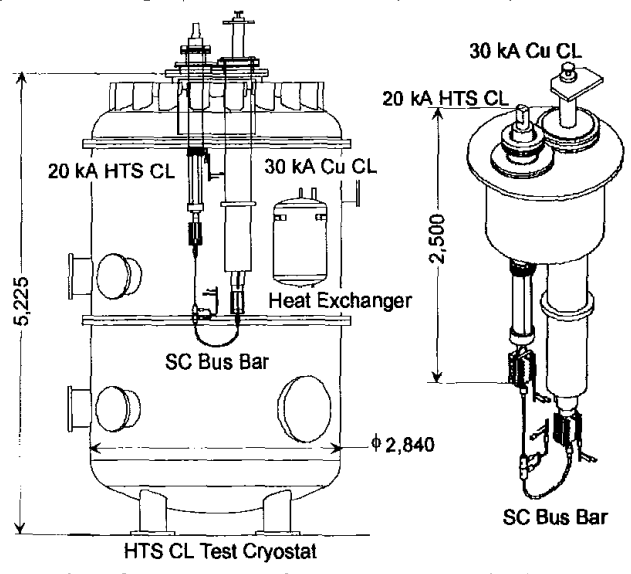

Fig. 2. Drawing of a test cryostat for the HTS current lead.

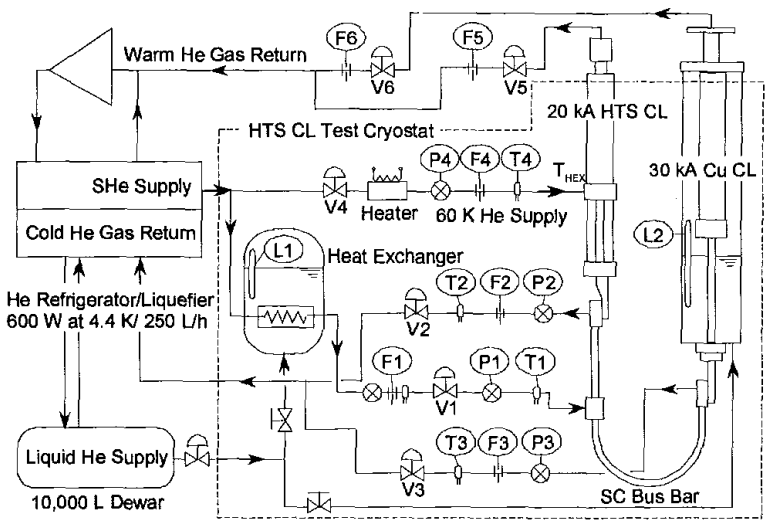

Fig. 3. Schematic of the cryogenic system for testing the HTS current lead.

The performance tests of the HTS current lead were successfully conducted. The critical current was measured approximately $30 \mathrm{kA}$ by maintaining the connection of the copper-to-HTS part, T4, at $85 \mathrm{~K}$ as shown in Fig. 5.

TABLE I

PROGRESS OF THE EXPERIMENT FOR 20 KA HTS CURRENT LEAD

\begin{tabular}{|c|c|}
\hline Date & Test items \\
\hline May 30 & Start He refrigerator and HTS current lead cool-down \\
\hline May 31 & Continue the cool-down \\
\hline June 1 & $\begin{array}{l}\text { Temperature profile measurements with zero current } \\
\text { Temperature profile measurements with nonzero current } \\
\text { T4: } 50 \mathrm{~K} \\
\mathrm{I}: \quad 0 \mathrm{kA} \rightarrow 10 \mathrm{kA} \rightarrow 15 \mathrm{kA} \rightarrow 20 \mathrm{kA} \rightarrow 0 \mathrm{kA} \\
\text { F4: } 0.6 \mathrm{~g} / \mathrm{s} \rightarrow 0.87 \mathrm{~g} / \mathrm{s} \rightarrow 1.17 \mathrm{~g} / \mathrm{s} \rightarrow 1.52 \mathrm{~g} / \mathrm{s} \rightarrow 0.6 \mathrm{~g} / \mathrm{s} \\
\text { Hold time of each current: } 60 \mathrm{~min}\end{array}$ \\
\hline June 2 & $\begin{array}{l}\text { Temperature profile measurements with nonzero current } \\
\text { T4: } 60 \mathrm{~K} \\
\mathrm{I}: \quad 0 \mathrm{kA} \rightarrow 20 \mathrm{kA} \rightarrow 0 \mathrm{kA} \\
\mathrm{F} 4: \quad 0.74 \mathrm{~g} / \mathrm{s} \rightarrow 2.0 \mathrm{~g} / \mathrm{s} \rightarrow 0.74 \mathrm{~g} / \mathrm{s} \\
\text { Hold time of } 20 \mathrm{kA}: 60 \mathrm{~min} \\
\text { Stop He refrigerator }\end{array}$ \\
\hline June 5 & Restart He refrigerator and HTS current lead cool-down \\
\hline June 6 & $\begin{array}{l}\text { Critical current measurements } \\
\text { T4:85 K, F4: } 1 \mathrm{~g} / \mathrm{s} \rightarrow \text { quench from HTS at } 30.8 \mathrm{kA}\end{array}$ \\
\hline June 7 & $\begin{array}{l}\text { Critical current measurements } \\
\text { T4: } 85 \mathrm{~K}, \mathrm{~F} 4: 1 \mathrm{~g} / \mathrm{s} \rightarrow \text { quench from HTS at } \sim 29 \mathrm{kA} \\
\text { Emergency test with zero mass flow } \\
\mathrm{T} 4: \quad 60 \mathrm{~K} \text { (initial value) } \\
\mathrm{I}: \quad 0 \mathrm{kA} \rightarrow 20 \mathrm{kA} \text { (Hold the current until quench) } \\
\mathrm{F} 4: \quad 0.74 \mathrm{~g} / \mathrm{s} \rightarrow 2.0 \mathrm{~g} / \mathrm{s} \rightarrow 0 \mathrm{~g} / \mathrm{s} \\
\text { It took about } 15 \mathrm{~min} \text { to quench after helium flow stopped }\end{array}$ \\
\hline June 8 & $\begin{array}{l}\text { Heat load measurements with a different T4 temperature } \\
\text { Fast ramp up and down test } \\
\text { T4: } 60 \mathrm{~K} \\
\mathrm{I}: 0 \mathrm{kA} \rightarrow 40 \mathrm{kA} \rightarrow 0 \mathrm{kA} \text {, ramp rate } 1 \mathrm{kA} / \mathrm{s} \\
\text { Hold time of } 40 \mathrm{kA}: 10 \mathrm{sec} \\
\text { Heat load measurements with a different T4 temperature }\end{array}$ \\
\hline June 9 & $\begin{array}{l}\text { Heat load measurements with a different T4 temperature } \\
\text { Temperature profile measurements with nonzero current } \\
\text { T4: } \quad 60 \mathrm{~K} \\
\begin{array}{l}\mathrm{I}: \quad 0 \mathrm{kA} \rightarrow \quad 20 \mathrm{kA} \quad \rightarrow 0 \mathrm{kA} \\
\mathrm{F} 4: \quad 0.74 \mathrm{~g} / \mathrm{s} \rightarrow 2.0 \mathrm{~g} / \mathrm{s} \rightarrow 2.5 \mathrm{~g} / \mathrm{s} \rightarrow 0.74 \mathrm{~g} / \mathrm{s} \\
\text { Hold time of } 20 \mathrm{kA}: 120 \mathrm{~min}\end{array}\end{array}$ \\
\hline
\end{tabular}



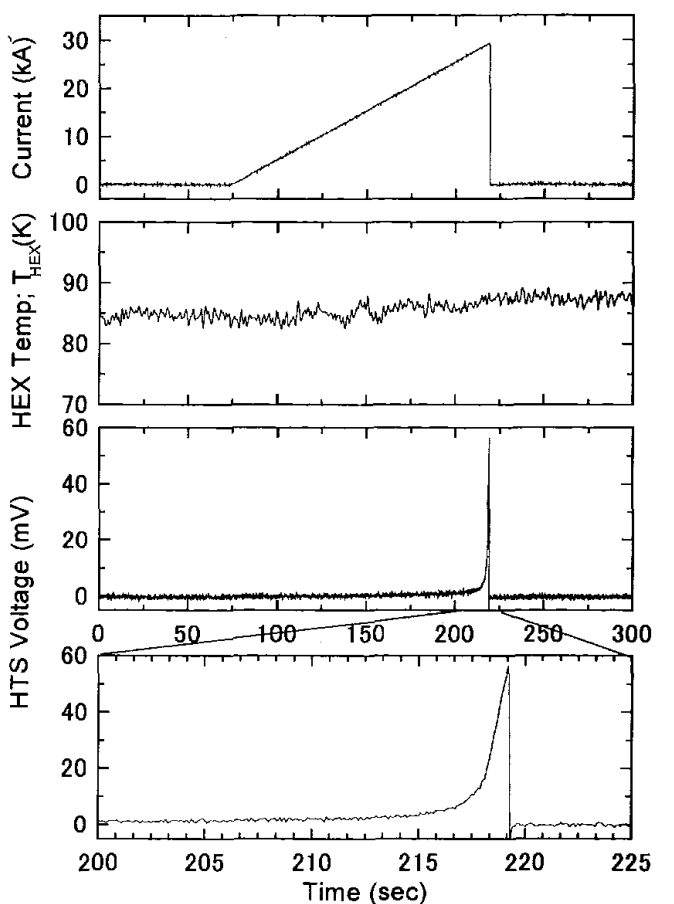

Fig. 4. Voltage signal of the HTS part with temperature of the metal-to-HTS connection; $\mathrm{T}_{\mathrm{HEX}}$ during the critical current measurement.

The $40 \mathrm{kA}$ excitation current with $10 \mathrm{~s}$ hold time was achieved by a fast ramp up test with $1 \mathrm{kA} / \mathrm{s}$ and $\mathrm{T} 4$ at $60 \mathrm{~K}$, although the HTS current lead was design to the nominal current of $20 \mathrm{kA}$ with the operating temperature at the HTS upper end of $70 \mathrm{~K}$. These test results demonstrated the high potential of the HTS current lead using $\mathrm{Ag} / \mathrm{Au}$ stabilized Bi-2223 tapes.

\section{BI-2212 BUlk FABRICATED By Diffusion Process}

Bi-2212 $\left(\mathrm{Bi}_{2} \mathrm{Sr}_{2} \mathrm{CaCu}_{2} \mathrm{O}_{8+\mathrm{X}}\right)$ bulk fabricated by the diffusion process is expected as an alternative material for HTS current leads. Bi-2212 oxide layer has been synthesized by diffusion process between $\mathrm{Bi}$-free 0212 substrate and $\mathrm{Bi}-\mathrm{Cu} 2001$ coating layer. A uniform $\mathrm{Bi}-2212$ diffusion layer about $150 \mu \mathrm{m}$ in thickness is synthesized around both outside and inside of the cylindrical tube. High current transport tests of a $\mathrm{Bi}-2212$ tube fabricated by diffusion process have been conducted in NIFS with Tokai University [2].

Fig. 5 shows a photograph of a $\mathrm{Bi}-2212$ tube $20 / 16 \mathrm{~mm}$ in outer/inner diameter and $55 \mathrm{~mm}$ in length. The surface of the tube with $30 \mathrm{wt} \% \mathrm{Ag}$ addition to the coating layer was covered with the precipitated $\mathrm{Ag}$ after diffusion reaction. The $\mathrm{Ag}$ precipitated on the surface about $50 \mu \mathrm{m}$ thick was removed using etching reagent except for both ends which enable low resistive contact to the copper electrodes. Fig. 6 shows a schematic drawing of the sample holder for the high current transport test. The tube specimen was soldered to the copper electrodes at both ends. One electrode was attached directly to the lower terminal of the current lead while the other electrode was connected to the current lead via flexible

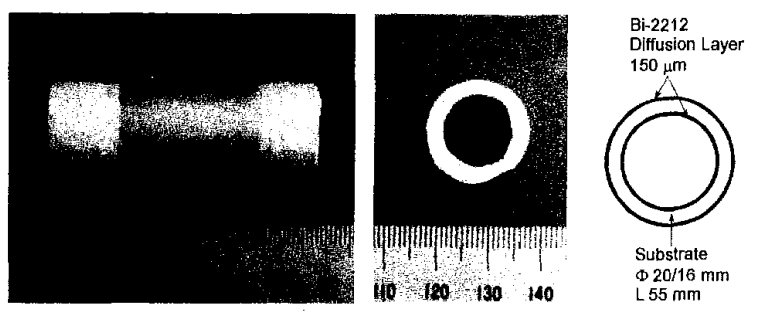

Fig. 5. A photograph of a Bi-2212 tube specimen $20 / 16 \mathrm{~mm}$ in outside/inside diameter and $55 \mathrm{~mm}$ in length.

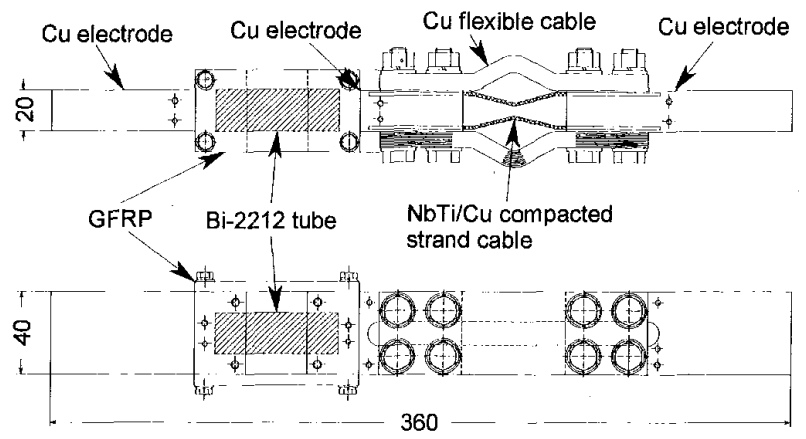

Fig. 6. A schematic drawing of the sample holder for the high current transport test.

line with $\mathrm{NbTi} / \mathrm{Cu}$ compacted strand cables to avoid mechanical damage caused by thermal contraction.

The high current transport tests have been conducted in liquid helium. The Bi-2212 tube was successfully excited up to $6.25 \mathrm{kA}$ and was broken at $6.38 \mathrm{kA}$. No voltage was observed at the HTS part just before the mechanical break. However, both joint voltages were about $1 \mathrm{mV}$ at $6 \mathrm{kA}$, which means high contact resistance of $0.17 \mu \Omega$ due to insufficient soldering between $\mathrm{Bi}-2212$ tube and copper electrodes. The quench was initiated at the joint. Therefore, the critical current density of the Bi-2212 diffusion layer can be estimated to be more than $380 \mathrm{~A} / \mathrm{mm}^{2}$ at $4.2 \mathrm{~K}$.

We are progressing to the next stage based on the success of the preliminary tests. Development and high current transport tests are planned using a larger size bulk tube with an outer/inter diameter of $28 / 20 \mathrm{~mm}$ and a length of $200 \mathrm{~mm}$. Mechanical reinforcement of a bulk tube is also investigated by wrapping glass epoxy tapes on the outer side of the tube or by adding reinforcing materials to the ceramic substrate.

\section{V.PRototyPE YBCO CURRENT FEEDTHROUGH}

An HTS current feedthrough from $4.4 \mathrm{~K}$ to $1.8 \mathrm{~K}$ with high current capacity and low heat leak is required for the helical coils of LHD in the phase II experiment. The helical coils cooled with He II $(1.8 \mathrm{~K})$ and the superconducting bus lines cooled with two-phase helium $(4.4 \mathrm{~K})$ are connected in the LHD cryostat where the maximum stray field is about $1 \mathrm{~T}$. An $\mathrm{YBa}_{2} \mathrm{Cu}_{3} \mathrm{O}_{\mathrm{X}}$ (YBCO) bulk fabricated by the modified quench and melt growth (QMG) process is selected as a promising material for the HTS current feedthrough because of its large 


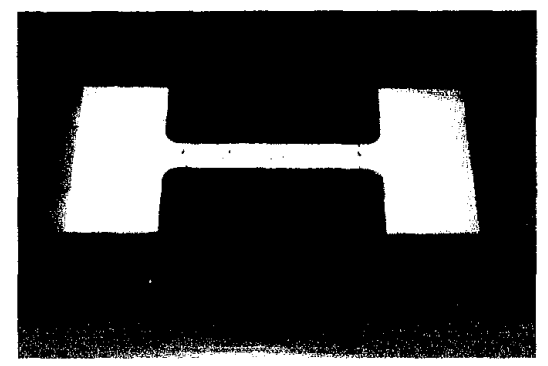

Fig. 7. " $\mathrm{H}$ " shaped YBCO bulk conductor $(60 \mathrm{~mm}$ wide, $140 \mathrm{~mm}$ long and $10 \mathrm{~mm}$ thick) for the prototype HTS current feedthrough.
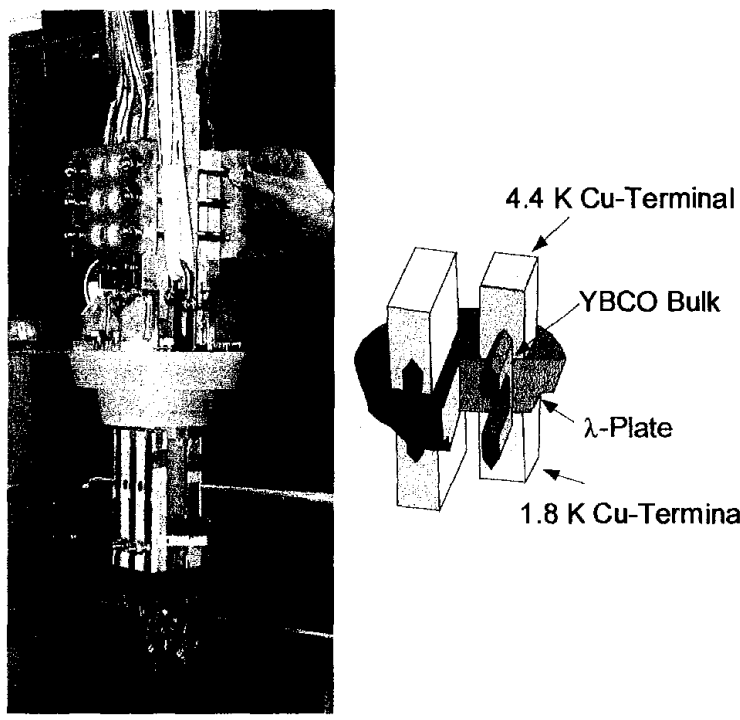

1.8 K Cu-Terminal

Fig. 8. Assembled prototype HTS current feedthrough.

critical current density under the magnetic field and low thermal conductivity.

As a preliminary experiment to study the feasibility of YBCO bulk for a HTS current feedthrough, high current transport tests were conducted in NIFS together with Kyushu University [3]. " $\mathrm{H}$ " shaped samples with $40 \mathrm{~mm}$ wide, $50 \mathrm{~mm}$ long and $7 \mathrm{~mm}$ thick were cut from the disk-shaped YBCO bulk $65 \mathrm{~mm}$ in diameter and $15 \mathrm{~mm}$ thick. Both sides of " $\mathrm{H}$ " shaped sample were soldered to copper electrodes. The cross section of the " $\mathrm{H}$ " sample straight part "_" is $7 \mathrm{~mm} \times 7 \mathrm{~mm}$. We succeeded in dc operation a high current transport of this sample up to $25 \mathrm{kA}$ at $4.2 \mathrm{~K}$.

According to the results, we decided to construct a $20 \mathrm{kA}$ prototype HTS current feedthrough with YBCO bulk made by QMG process. The prototype HTS current feedthrough was designed for the large $\mathrm{He}$ II cryostat in the cryogenic laboratory of NIFS. Because the straight section of " $\mathrm{H}$ " shaped bulk should pass through the thick $\lambda$-plate of the cryostat, the geometrical dimensions of the bulk must be larger than the preliminary test sample. Therefore, we have investigated a fabrication process of the high quality YBCO bulk and have succeeded to obtain a bulk conductor $60 \mathrm{~mm}$ wide, $140 \mathrm{~mm}$ long and $10 \mathrm{~mm}$ thick from the material manufactured with a "H" shape as shown in Fig. 7.

Fig. 8 shows the assembled prototype HTS current feedthrough. A pair of the bulk conductors was imbedded in a GFRP center plug of the $\lambda$-plate. We have tested three types of prototype HTS current feedthroughs. Two of them were tested in the large He II cryostat and one was tested in the conductor test cryostat with normal liquid helium. During the cool down of feedthrough, the HTS conductors showed a transition to superconducting state. However, in the dc transport current tests, normal voltages were observed for current less than $2 \mathrm{kA}$. These degradations may be due to a mechanical damage in the HTS bulk during the manufacturing process, the assembling process or the cooling process.

The above problems occurred in connection with the increase of the bulk size. We are trying to establish a method to detect a defect in the bulk before assembling it. We are also considering mechanical reinforcement of the bulk. After that, we will try again to test a new type of YBCO current feedthrough.

\section{SUMMARY}

A joint experiment of a 20kA HTS current lead developed by FZK was conducted in NIFS with FZK, as collaboration in LIME. The performance tests were successfully conducted and demonstrated the high potential of the HTS current lead using $\mathrm{Ag} / \mathrm{Au}$ stabilized $\mathrm{Bi}-2223$ tapes.

A Bi- 2212 bulk fabricated by the diffusion process is expected as an alternative material for HTS current leads. A $\mathrm{Bi}-2212$ tube $20 / 16 \mathrm{~mm}$ in outer/inner diameter and $55 \mathrm{~mm}$ in length was successfully excited up to $6.25 \mathrm{kA}$ and the critical current density of the diffusion layer can be estimated more than $380 \mathrm{~A} / \mathrm{mm}^{2}$ at $4.2 \mathrm{~K}$. We are planning to test a large-size $\mathrm{Bi}-2212$ tube as a next stage.

A $20 \mathrm{kA}$ prototype YBCO current feedthrough from $4.4 \mathrm{~K}$ to $1.8 \mathrm{~K}$ was designed and tested in the large He II cryostat. During the de transport current tests, normal voltages were observed for current less than $2 \mathrm{kA}$ due to a mechanical damage in the HTS bulk. It is important to establish a method to detect a defect in the bulk before assembling it.

\section{ACKNOWLEDGMENT}

The authors wish to express their thanks to Prof. P. Komarek at FZK, Prof. M. Fujiwara at NIFS for their continuous encouragement and substantial support. We would like to thank Fuji Electric Co., Ltd and Nippon Steel Co. for their help to develop HTS current feeders.

\section{REFERENCES}

[1] R. Heller, K. Takahata, G. Friesinger, T. Mito, M. Tasca, A. Nishimura, S. Satoh, S. Yamada, "Test results of a $20 \mathrm{kA}$ current lead using $\mathrm{Ag} / \mathrm{Au}$ stabilized Bi-2223 tapes ", presented in this conference, 5LE02.

[2] Y. Yamada, M. Takiguchi, O. Suzuki, K. Tachikawa, A. Iwamoto, H. Tamura, and T. Mito, "Transport performance of Bi-2212 current leads prepared by a diffusion process", presented in this conference, 5 LB08

[3] K. Maehata, T. Taino, M. Mizokami, K. Ishibashi, M. Takeo, T. Mito, A. Iwamoto, S. Yamada, S. Satoh, O. Motojima, T. Shintomi, M. Morita and T. Tokunaga, "High Current transport test of a YBCO bulk conductor up to $25 \mathrm{kA}$ ", IEEE Trans. Applied Superconductivity, Vol. 9 (1999) pp.1281-1284. 